\title{
Endoscopic sleeve gastroplasty versus intragastric balloon insertion: efficacy, durability, and safety
}

\author{
Authors \\ Lea Fayad', Lawrence J. Cheskin², Atif Adam², Dilhana S. Badurdeen', Christine Hill², Abhishek Agnihotri ${ }^{1}$, \\ Margo Dunlap ${ }^{1}$, Cem Simsek ${ }^{1}$, Mouen A. Khashab ${ }^{1}$, Anthony N. Kalloo ${ }^{1}$, Vivek Kumbhari ${ }^{1}$ \\ Institutions \\ 1 Johns Hopkins University School of Medicine, Baltimore, \\ Maryland, USA \\ 2 Johns Hopkins Bloomberg School of Public Health, \\ Baltimore, Maryland, USA \\ submitted 27.5.2018 \\ accepted after revision 14.1.2019 \\ Bibliography \\ DOI https://doi.org/10.1055/a-0852-3441 \\ Published online: 6.3.2019 | Endoscopy 2019; 51: 532-539 \\ (c) Georg Thieme Verlag KG Stuttgart · New York \\ ISSN 0013-726X \\ Corresponding author \\ Vivek Kumbhari, MD, Johns Hopkins Medicine, Division \\ of Gastroenterology and Hepatology, 1800 Orleans Street, \\ Sheikh Zayed Tower, 7th, floor, Suite 7125B, Baltimore, \\ MD 21287, USA \\ vkumbhari@gmail.com

\section{ABSTRACT} \\ Background Intragastric balloon (IGB) placement and \\ endoscopic sleeve gastroplasty (ESG) are reported to be \\ Methods: This was a retrospective review of prospectively \\ collected data from consecutive patients between Decem- \\ ber 2015 and October 2017 who underwent IGB or ESG at a \\ single academic center. Fluid-filled IGBs implanted for a 6- \\ month duration were used. IGB and ESG patients were sub- \\ jected to identical post-procedure dietary instructions and \\ follow-up protocols. Body weight was recorded at 1, 3, 6, \\ and 12 months post-procedure. \\ Results A total of 47 patients underwent IGB insertion and \\ 58 underwent ESG. The IGB cohort had a lower baseline \\ body mass index (BMI) than the ESG (34.5 vs. $41.5 \mathrm{~kg} / \mathrm{m}^{2}$; \\ $P<0.001)$ and a significantly lower proportion of men $(2.1$ \\ $\%$ vs. $41.4 \%$; $P<0.001$ ). IGB patients showed a mean (stand- \\ ard deviation [SD]) percentage total body weight loss (\% \\ TBWL) that was significantly lower than ESG patients at 1 \\ month $(6.6 \%$ [2.6\%] vs. $9.9 \%$ [2.4\%]; $P<0.001), 3$ months \\ (11.1\% [4.4\%] vs. $14.3 \%$ [4.6\%]; $P=0.004), 6$ months \\ (15.0\% [7.6\%] vs. $19.5 \%$ [5.7\%]; $P=0.01)$, and 12 months \\ (13.9\% [9.0\%] vs. $21.3 \%$ [6.6\%]; $P=0.005)$. The IGB cohort \\ also experienced significantly more adverse events compar- \\ ed with the ESG ( $17 \%$ vs. $5.2 \%$; $P=0.048)$. \\ Conclusions IGB placement and ESG result in clinically \\ meaningful weight loss. However, ESG appears to provide \\ clinically superior and more enduring weight loss with few- \\ er adverse events compared with an IGB.
} safe and effective endoscopic bariatric therapies. This study aimed to compare the patient demographics and therapeutic outcomes between the IGB and ESG procedures.

\section{Introduction}

Obesity remains a global public health concern without a satisfactory solution [1]. Endoscopic bariatric therapies (EBTs) have gained standing among the armamentarium of weight loss therapies because of their minimally invasive nature, reversibility, and applicability in patient populations otherwise ineligible for bariatric surgery [2]. Endoscopic sleeve gastroplasty (ESG) is an EBT that has achieved significant success in the past few years; therefore, it is timely to compare it to the well-established intragastric balloon (IGB) therapy, the most commonly performed EBT in the United States and internationally [3-5].

The IGB is a space-occupying device that has been safely used to induce weight loss [3-5]. A systematic review and meta-analysis reported that patients undergoing IGB therapy achieved $13.16 \%$ total body weight loss (TBWL) at 6 months [6]. A more recent review demonstrated a 9.7\% TBWL at 6 months, with decreasing efficacy after 6 months [4]. The primary limitation of IGB therapy is the common occurrence of weight regain $[7,8]$, even in a clinical trial setting $[9,10]$, which is thought to be due to the necessary removal of the balloon at 6 months. The most common adverse events associated with the IGB are nausea/vomiting, abdominal pain, and gastroesophageal reflux disease (GERD) [3].

There are currently two FDA-approved, fluid-filled IGBs available in the USA: the ReShape Integrated Dual Balloon System (ReShape Lifesciences, San Clemente, California, USA) and the Orbera Intragastric Balloon System (Apollo Endosurgery, Austin, Texas, USA; previously BioEnterics Intragastric Balloon). 
Although no head-to-head trial has been performed to compare the ReShape to the Orbera, published prospective evidence has found roughly comparable weight loss and adverse event outcome data for the two systems $[5,10]$. Additionally, real-world multicenter studies have corroborated the weight loss and adverse outcomes for IGBs with a \%TBWL at 3 and 6 months, respectively, of $8.8 \%$ and $11.4 \%$ for the Reshape [11] and $8.5 \%$ and $11.8 \%$ for Orbera [12].

Unlike IGB therapy, ESG is a volume-reduction procedure performed using an endoscopic suturing system to reduce the stomach lumen into a tubular configuration $[13,14]$. A multicenter study by Lopez-Nava et al. [15] showed a \%TBWL of $15.2 \%$ at 6 months. Serious adverse events occurred in $2 \%$ of patients, but were managed successfully without surgical intervention. Another international multicenter study by Sartoretto et al. [16] found a $14.9 \%$ TBWL at 6 months, with a $2.7 \%$ rate of serious adverse events, confirming that ESG is a reproducible and generalizable technique internationally.

Both the ESG and IGB procedures have been shown to be relatively safe and efficacious. Electing for one procedure over the other has been solely based on patient preference, often driven by relative costs. We were uniquely positioned to compare the two procedures as both are performed at our institution, where patients are subjected to identical post-procedure dietary instructions and follow-up protocols, making any differences seen likely to be due to the procedures themselves. We hypothesized that ESG would result in superior and more enduring weight loss compared with the IGB.

\section{Methods}

\section{Patient population}

This is a retrospective review of prospectively collected data under IRB00122220 and IRB00120291. Consecutive patients who underwent IGB placement or ESG between December 2015 and October 2017 at a single academic center (Johns Hopkins Medical Institutions) were included.

All patients had an initial consultation where they were provided with information on various weight loss options, including diet and exercise programs, pharmacotherapy, EBT, and bariatric surgery. Patients who were ineligible for bariatric surgery or elected not to undergo bariatric surgery were subsequently offered endoscopic procedures. Endoscopic procedures comprised ESG, IGB insertion, intragastric botulinum toxin injection, and aspiration therapy with the AspireAssist (Aspire Bariatrics, King of Prussia, Pennsylvania, USA). The technicality of all endoscopic treatment options, benefits, risks, and adverse outcomes were reviewed. The decision to undergo ESG vs. IGB placement was made by the patient, unless a contraindication existed. All procedures were self-pay, with the IGB program priced at approximately US\$8000 and the ESG program approximately US\$16 000 .

\section{Periprocedural and post-procedural care}

All procedures were performed by a single endoscopist experienced in endoscopic suturing (V.K.). The procedures were same-day procedures with identical pre- and post-procedure care, including diet, medications, and frequency of allotted nutritional visits for follow-up.

The preoperative medications were omeprazole $40 \mathrm{mg}$ for 1 week and a single dose of aprepitant (Emend) $125 \mathrm{mg}$ given 3 hours before the procedure. All patients were prescribed a liquid diet from 1 day before and nothing by mouth after midnight on the night prior to their procedure.

The post-op medications were aprepitant $80 \mathrm{mg}$ once on the first day post-procedure, hyoscyamine (Levsin) $0.125 \mathrm{mg}$ every 6 hours as needed for cramping, and ondansetron (Zofran) 4 mg every 6 hours as needed for nausea. Omeprazole $40 \mathrm{mg}$ was continued daily for 6 weeks post-procedure. Patients also received $2-3 \mathrm{~L}$ of fluid during their stay in the endoscopy suite. Patients were instructed to remain on strict liquid diet for 3 days post-operatively, after which they were transitioned, at 2 weekly intervals, into pureed diet, soft diet, and ultimately solid diet if well tolerated.

All patients were enrolled post-procedure into a comprehensive weight management program at the Johns Hopkins Weight Management Center. The program consisted of 12 visits over 1 year with a multidisciplinary team comprising a medical weight loss physician, registered dietitian, exercise physiologist, and behavioral psychologist. Patients were encouraged to actively participate in this program.

\section{Intragastric balloon (IGB) insertion}

Indications for IGB placement were a body mass index (BMI)> $27 \mathrm{~kg} / \mathrm{m}^{2}$ in patients who had previously been unsuccessful in losing weight through diet, and/or exercise, and/or medications. Contraindications included a history of gastroesophageal surgery and active anticoagulation.

The choice of ReShape vs. Orbera balloon was based on patient preference. All procedures were performed in the endoscopy suite with the patient under monitored anesthesia care. The balloons were inserted endoscopically as per the manufacturers' recommendations. For the ReShape balloon, $450 \mathrm{~mL}$ of normal saline was used in each balloon, except in patients shorter than 64.5 inches, who received $375 \mathrm{~mL}$ in each balloon ( $\triangleright$ Fig. 1). The Orbera balloon was filled with $600-650 \mathrm{~mL}$ of normal saline if the patient was taller than 64.5 inches and $550 \mathrm{~mL}$ if shorter ( $\triangleright$ Fig. 2). Balloons were extracted 6 months after insertion, or earlier in the event of intolerance or adverse events.

\section{Endoscopic sleeve gastroplasty (ESG) procedure}

Indications for ESG were a BMI $>30 \mathrm{~kg} / \mathrm{m}^{2}$ in patients who had been previously unsuccessful in losing weight through diet, and/or exercise, and/or medications. Contraindications included a history of gastric cancer, a family history of gastric cancer, active Helicobacter pylori infection, active gastric ulcer, gastric intestinal metaplasia, vascular abnormalities, decompensated organ failure, prior foregut surgery, and pregnancy/lactation.

All ESG procedures were performed with the patient under general anesthesia. The technique used was the same as that described by Sartoretto et al. [16] using the OverStitch fullthickness endoscopic suturing system (Apollo Endosurgery, Austin, Texas, USA). Before suturing, argon plasma coagulation 


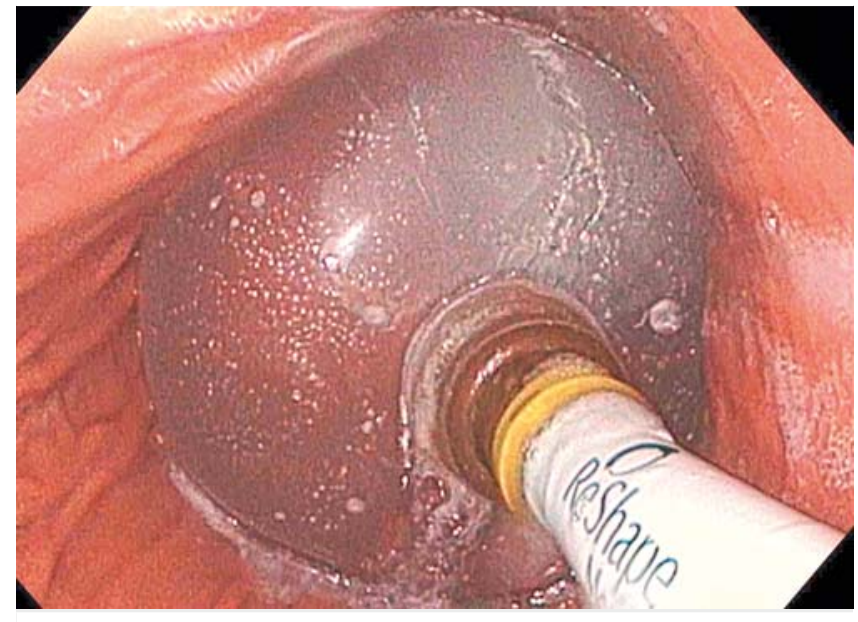

- Fig. 1 Endoscopic image showing inflation of the ReShape balloon.

was used to mark the intended suture line on the anterior and posterior walls of the stomach. Sutures were placed in a retrograde fashion starting from the incisura angularis and progressing to the fundus, reaching up to $1 \mathrm{~cm}$ from the gastroesophageal junction. Six to nine sutures were used per patient and six to nine full-thickness bites were taken with each suture. The bites were taken lateral to the demarcated suture line, with the following pattern; anterior wall to greater curvature to posterior wall, and then repeated in the opposite direction $1 \mathrm{~cm}$ proximally. The needle was then released and the suture was secured with a cinching device ( $\triangleright$ Fig. 3 ).

\section{Outcomes}

Patient demographics, initial weight, and comorbidities such as diabetes, hypertension, GERD, and obstructive sleep apnea were collected. The patients were contacted by the clinical nurse via phone on days 1,2 , and 3 post-procedure, and at 1 , 3,6 , and 12 months post-procedure.
Primary outcomes were \%TBWL at each time point and adverse events recorded at follow-up. Adverse events were recorded only if they required admission to hospital. Nausea, vomiting, and abdominal discomfort were an expected part of the post-operative course and were not recorded, with patients given necessary medications and instructions for their management in advance.

\section{Statistical analysis}

Descriptive statistics for all demographic and clinical variables are reported as mean (standard deviation [SD]), or proportion where appropriate. For categorical variables, the chi-squared test and Fisher's exact test were used. Student's $t$ test or Mann Whitney $U$ test were used for continuous variables. Chi-squared tests were performed for all univariate analyses. All variables were tested for normality using the Shapiro - Wilk test. Multiple factor regression was done to predict \%TBWL between ESG and IGB groups based on patient age at time of study, BMI at baseline, and sex. All statistical analyses were conducted using STATA 14.0 (StataCorp LP, College Station, Texas, USA). A P value of $<0.05$ was considered significant.

\section{Results}

A total of 47 patients underwent IGB insertion and 58 underwent ESG. In the IGB group, 14 patients received a ReShape dual intragastric balloon and 33 an Orbera intragastric balloon.

- Table 1 shows the baseline characteristics of the patients in both groups. The mean age was comparable between the two groups; however, baseline BMI was significantly lower in the patients undergoing IGB placement compared with those undergoing ESG $\left(34.5 \mathrm{~kg} / \mathrm{m}^{2}\right.$ vs. $\left.41.5 \mathrm{~kg} / \mathrm{m}^{2} ; P<0.001\right)$. In addition, the IGB group had a significantly lower proportion of men than the ESG group ( $2.1 \%$ vs. $41.4 \%$; $P<0.001)$. Patients who underwent IGB placement had a significantly lower proportion of obstructive sleep apnea at baseline compared with patients in the ESG group ( $2.1 \%$ vs. $15.5 \% ; P=0.02)$. The proportion of pa-

- Table 1 Baseline characteristics of the 105 patients who underwent either endoscopic sleeve gastrectomy (ESG) or intragastric balloon (IGB) insertion.

\begin{tabular}{|c|c|c|c|}
\hline & $\begin{array}{l}\text { ESG } \\
(n=58)\end{array}$ & $\begin{array}{l}\text { IGB } \\
(n=47)\end{array}$ & $P$ value \\
\hline Age, mean (SD), years & $48.2 \quad(11.8)$ & $47.7 \quad(12.4)$ & 0.90 \\
\hline Sex, male, $\mathrm{n}(\%)$ & $24 \quad(41.4 \%)$ & $1 \quad(2.1 \%)$ & $<0.001$ \\
\hline BMI, mean (SD), kg/m² & $41.5 \quad(8.2)$ & $34.5 \quad(6.7)$ & $<0.001$ \\
\hline \multicolumn{4}{|l|}{ Comorbidities } \\
\hline - Type 2 diabetes mellitus, n (\%) & $3 \quad(5.2 \%)$ & $4 \quad(8.5 \%)$ & 0.51 \\
\hline - Hypertension, n (\%) & $17 \quad(29.3 \%)$ & $13(27.7 \%)$ & 0.80 \\
\hline - GERD, n (\%) & $11 \quad(19.0 \%)$ & $4 \quad(8.5 \%)$ & 0.12 \\
\hline - Obstructive sleep apnea, n (\%) & $9 \quad(15.5 \%)$ & $1 \quad(2.1 \%)$ & 0.02 \\
\hline
\end{tabular}



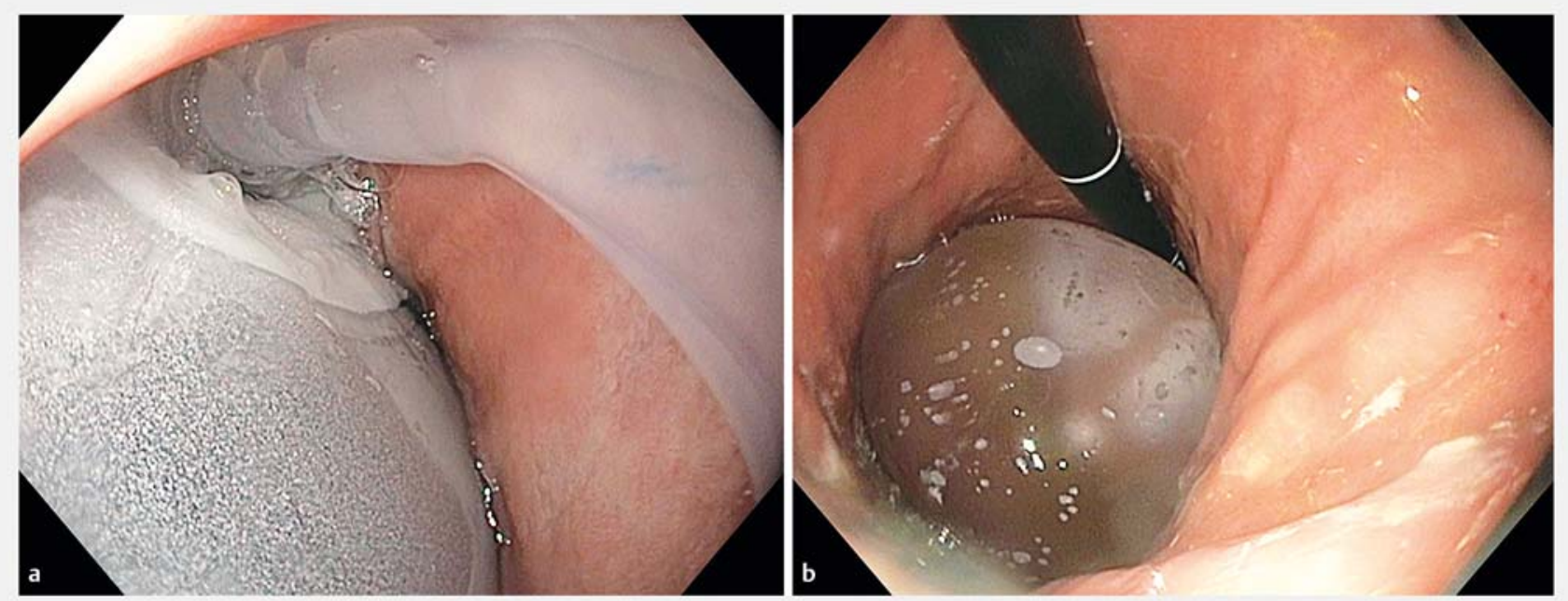

- Fig. 2 Endoscopic images showing the Orbera balloon: a being inflated; $\mathbf{b}$ after deployment.
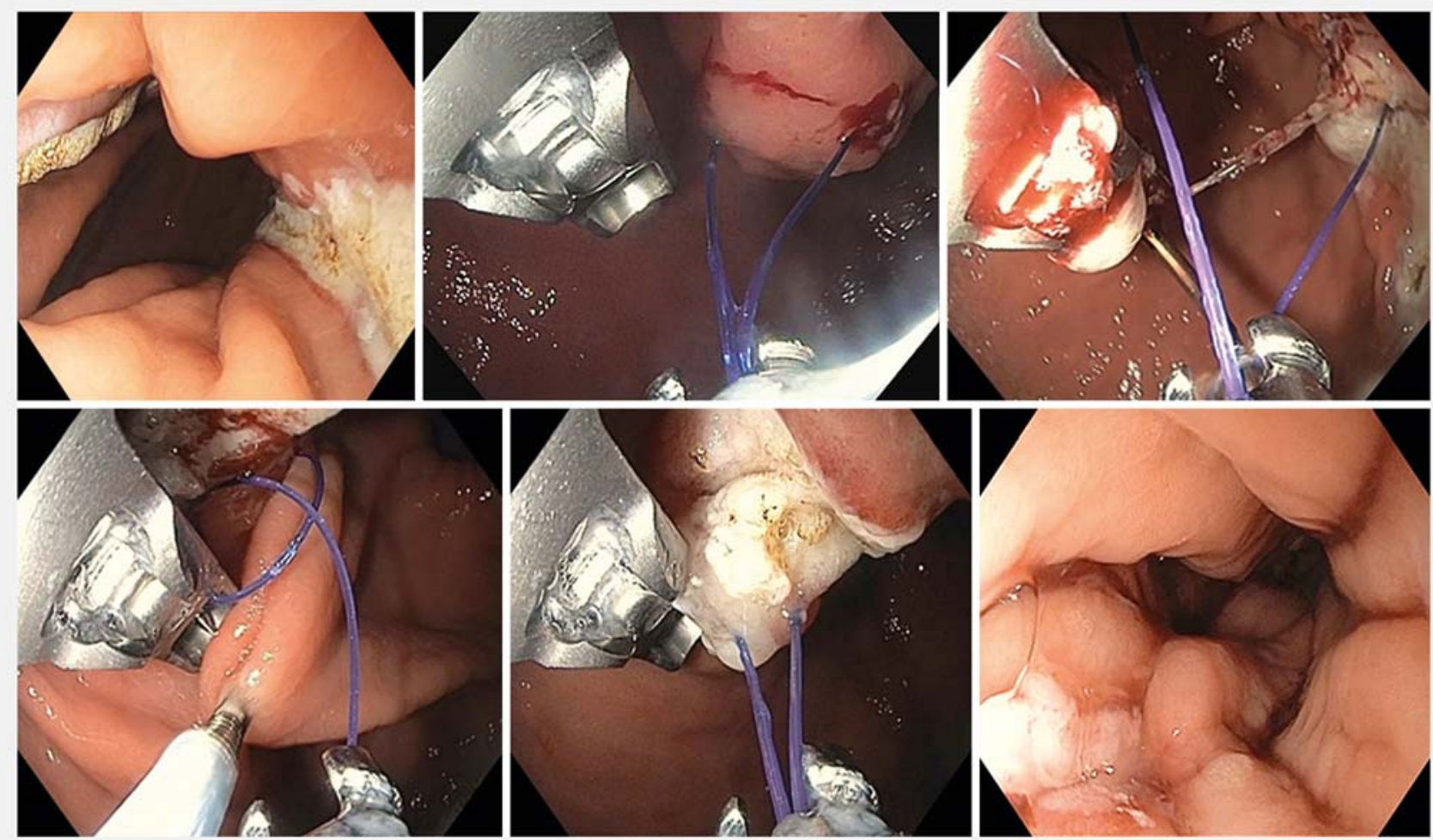

- Fig. 3 Endoscopic images of the endoscopic sleeve gastroplasty (ESG) procedure: a argon plasma coagulation (APC) markings are placed to help guide the bites; $\mathbf{b}$ the initial bite is performed (note the amount of tissue contained within the full-thickness bite); $\mathbf{c}$ the suture is then reloaded onto the needle driver; $\mathbf{d}$ a tissue helix (Apollo Endosurgery, Austin, Texas, USA) is used to retract the tissue; e the final bite is performed back on the anterior wall; $\boldsymbol{f}$ the appearance of the gastric lumen after ESG has been completed.

tients with GERD, type 2 diabetes mellitus, and hypertension at baseline were similar between the two groups ( $\triangleright$ Table 1 ).

- Table 2 and $>$ Fig. 4 show the \%TBWL at each time point compared with the baseline. IGB patients showed a significantly lower mean \%TBWL than ESG patients at 1 month (6.6\% [2.6\%] vs. $9.9 \%[2.4 \%] ; P<0.001), 3$ months $(11.1 \%[4.4 \%]$ vs. $14.3 \%$ [4.6\%]; $P=0.004), 6$ months (15.0\% [7.6\%] vs. $19.5 \%$ [5.7\%]; $P$ $=0.01$ ), and 12 months (13.9\% [9.0\%] vs. $21.3 \%$ [6.6\%]; $P=$ $0.005)$. This difference persisted after controlling for sex, age, and baseline BMI. Of note, between 6 and 12 months, patients 
in the IGB cohort had a 7.3 pound (12.7 pound) increase in weight, whereas patients in the ESG cohort lost on average 4.3 pounds ( 11.8 pounds) in weight $(P=0.007)$. Multifactor regression established that undergoing ESG could significantly predict higher \%TBWL at follow-up of 1, 3, 6, and 12 months ( $\triangleright$ Table 3). There were no differences in \%TBWL between men and women when looking at the follow-up of either the ESG or IGB groups.

There was a significantly greater rate of adverse events in the IGB group compared with the ESG group (17\% vs. $5.2 \%$; $P$ $=0.048)$. Adverse events following IGB insertion included early removal because of: nausea and vomiting $(n=4 ; 8.5 \%)$, abdominal pain ( $n=1 ; 2.1 \%)$, abdominal pain with gastritis $(n=1$; $2.1 \%$ ), balloon hyperinflation $(n=1 ; 2.1 \%)$, and a non-obstructing balloon resting in the antrum $(n=1 ; 2.1 \%)$. Adverse events for ESG included upper gastrointestinal bleeding (UGIB) in two patients and a perigastric fluid collection in one patient. One patient with UGIB was managed with a diagnostic endoscopy and admission for 48-hour monitoring; the other was medically managed. The perigastric fluid collection was successfully managed medically with antibiotics, and follow-up imaging at 3 weeks showed complete resolution, as illustrated in an earlier published case report [17]. No adverse events requiring surgical intervention occurred in either group and there was no mortality associated with either procedure.

\section{Discussion}

IGB placement and ESG have gained significant popularity and traction over the last 2 years, with various publications demonstrating efficacy and safety for both $[5,8,10,15,18]$. However, until now, there have been no studies comparing the outcomes of these two EBTs. While cross-center comparisons are limited by variability in post-procedure dietary instructions and preand post-procedure care, this study is uniquely positioned to ascertain the impact of the endoscopic therapy alone on weight loss outcomes over a 12-month period.

ESG resulted in superior weight loss compared with IGB placement over 12 months post-procedure. In our study, the 6-month \%TBWL of $19.5 \%$ in the ESG group was consistent with the values of $15.2 \%$ and $14.9 \%$ previously reported by Lopez-Nava et al. [15] and Sartoretto et al. [16], respectively. Our 12 -month follow-up \%TBWL is $21.3 \%$, similar to the outcomes of $17.5 \%$ and $17.4 \%$ previously reported by Graus et al. [19] and Kumar et al. [20], respectively. Our IGB group's 6-month \%TBWL of $15 \%$ was comparable with the $11.4 \%$ reported by Agnihotri et al. [12], and the $11.8 \%$ reported by Vargas at al. [18], although higher than the values reported by Ponce et al. (8.4\%) [5] and Courcoulas et al. (10.2\%) [10]. Our 12-month \% TBWL for the IGB group is $13.9 \%$, and within the TBWL range reported in the literature, as can be seen from the $14.7 \%$ reported by Agnihotri at al. [18]

Our study demonstrates that \%TBWL slows down at 6 months for ESG patients, and decreases after 6 months for IGB patients. In the IGB group, this can be explained by the balloon being removed at 6 months.
- Table 2 Total body weight loss of patients followed up at 1, 3, 6, and 12 months post-procedure.

\begin{tabular}{|c|c|c|c|c|}
\hline $\begin{array}{l}\text { Time post- } \\
\text { procedure }\end{array}$ & Procedure & $\begin{array}{l}\text { Patients } \\
\text { followed } \\
\text { up, n (\%) }\end{array}$ & $\begin{array}{l}\text { Mean \% } \\
\text { TBWL } \\
\text { (SD) }\end{array}$ & $P$ valu \\
\hline \multirow[t]{2}{*}{1 month } & ESG & $52(89.7 \%)$ & $9.9(2.4)$ & \multirow[t]{2}{*}{$<0.00$} \\
\hline & IGB & 43 (91.5\%) & $6.6(2.6)$ & \\
\hline \multirow[t]{2}{*}{3 months } & ESG & $37(63.8 \%)$ & $14.3(4.6)$ & \multirow[t]{2}{*}{0.004} \\
\hline & IGB & 35 (74.4\%) & $11.1(4.4)$ & \\
\hline \multirow[t]{2}{*}{6 months } & ESG & 25 (43.1\%) & $19.5(5.7)$ & \multirow[t]{2}{*}{0.01} \\
\hline & IGB & $43(91.4 \%)$ & $15.0(7.6)$ & \\
\hline \multirow[t]{2}{*}{12 months } & ESG & $21(36.2 \%)$ & $21.3(6.6)$ & \multirow[t]{2}{*}{0.005} \\
\hline & IGB & $20(42.6 \%)$ & $13.9(9.0)$ & \\
\hline
\end{tabular}

\%TBWL, percentage of total body weight loss; SD, standard deviation; ESG, endoscopic sleeve gastrectomy; IGB, intragastric balloon.

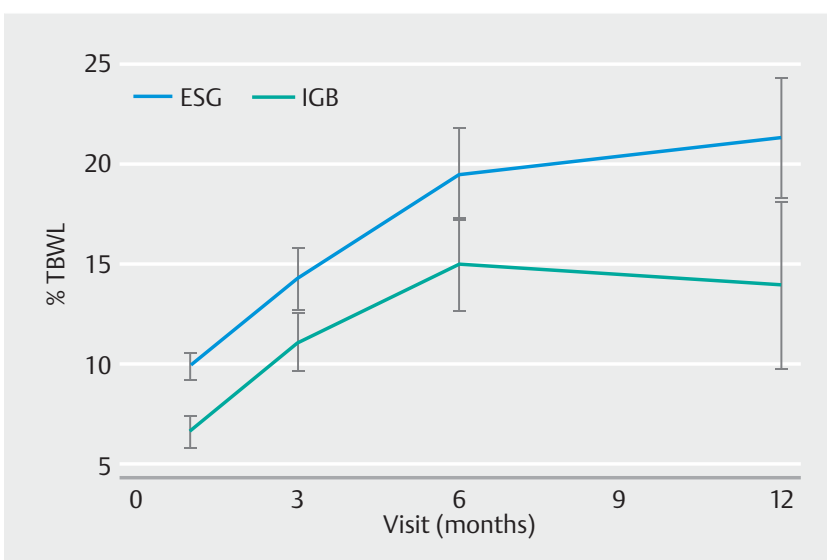

- Fig. 4 Percentage total body weight loss (\%TBWL) at 1, 3, 6, and 12 months after either endoscopic sleeve gastrectomy (ESG) or intragastric balloon (IGB) placement.

Weight recidivism after balloon removal is an expected outcome $[4,7,8]$, as demonstrated in a review by Tate and Geliebter [4], who reported a decline in efficacy of IGB therapy after the balloon's removal at 6 months and subsequent weight regain. Long-term data indicate that many patients have difficulty maintaining weight loss following treatment with an IGB [7, 8]. A large cohort study with 500 patients showed weight was regained from a mean (SD) body weight of $103.69 \mathrm{~kg}$ $(26.70 \mathrm{~kg})$ at time of removal to $112.53 \mathrm{~kg}(26.27 \mathrm{~kg}) 12$ months later [7]. An international multicenter study also showed a decrease in percentage excess weight loss (\%EWL) from $55.6 \%(58.8 \%)$ at 6 months to $29.1 \%(60.3 \%)$ at 3 years follow-up [8]. When stratifying which patients should receive an IGB vs. other therapy, weight recidivism after balloon removal should be considered. Patients who have been unsuccessful in achieving initial weight loss through diet and lifestyle or medications will most likely benefit from an IGB; however, 
- Table 3 Multifactor regression to predict percentage total body weight loss (\%TBWL) between the endoscopic sleeve gastrectomy (ESG) and intragastric balloon (IGB) groups based on patient age at time of study, body mass index (BMI) at baseline, and sex.

\begin{tabular}{|c|c|c|c|c|c|c|c|c|}
\hline & \multicolumn{2}{|l|}{ Model 1} & \multicolumn{2}{|l|}{ Model 2} & \multicolumn{2}{|l|}{ Model 3} & \multicolumn{2}{|l|}{ Model 4} \\
\hline & $\begin{array}{l}\text { Coefficient } \\
\text { (95\%CL) }\end{array}$ & $P$ value & $\begin{array}{l}\text { Coefficient } \\
(95 \% \mathrm{Cl})\end{array}$ & $P$ value & $\begin{array}{l}\text { Coefficient } \\
(95 \% \mathrm{Cl})\end{array}$ & $P$ value & $\begin{array}{l}\text { Coefficient } \\
(95 \% \mathrm{Cl})\end{array}$ & $P$ value \\
\hline \multicolumn{9}{|l|}{30 days } \\
\hline ESG & Reference & & Reference & & Reference & & Reference & \\
\hline IGB & $\begin{array}{l}-3.21 \\
(-4.24,-2.18)\end{array}$ & $<0.001$ & $\begin{array}{l}-3.59 \\
(-4.73,-2.46)\end{array}$ & $<0.001$ & $\begin{array}{l}-3.63 \\
(-4.76,-2.49)\end{array}$ & $<0.01$ & $\begin{array}{l}-3.24 \\
(-4.49,-2.00)\end{array}$ & $<0.001$ \\
\hline BMI & & & $\begin{array}{l}-0.06 \\
(-0.13,0.01)\end{array}$ & 0.10 & $\begin{array}{l}-0.06 \\
(-0.13,0.01)\end{array}$ & 0.09 & $\begin{array}{l}-0.06 \\
(-0.13,0.01)\end{array}$ & 0.12 \\
\hline Female & & & & & & & $\begin{array}{l}-0.02 \\
(-0.06,0.02)\end{array}$ & 0.37 \\
\hline Age & & & & & $\begin{array}{l}-0.02 \\
(-0.06,0.03)\end{array}$ & 0.40 & $\begin{array}{l}-1.14 \\
(-2.52,0.23)\end{array}$ & 0.10 \\
\hline \multicolumn{9}{|l|}{90 days } \\
\hline ESG & Reference & & Reference & & Reference & & Reference & \\
\hline IGB & $\begin{array}{l}-3.20 \\
(-5.33,-1.07)\end{array}$ & 0.004 & $\begin{array}{l}-3.95 \\
(-6.26,-1.63)\end{array}$ & 0.001 & $\begin{array}{l}-3.94 \\
(-6.27,-1.61)\end{array}$ & 0.001 & $\begin{array}{l}-3.58 \\
(-6.19,-0.98)\end{array}$ & 0.01 \\
\hline BMI & & & $\begin{array}{l}-0.12 \\
(-0.27,0.03)\end{array}$ & 0.12 & $\begin{array}{l}-0.12 \\
(-0.28,0.03)\end{array}$ & 0.12 & $\begin{array}{l}-0.12 \\
(-0.28,0.03)\end{array}$ & 0.12 \\
\hline Female & & & & & & & $\begin{array}{l}-0.90 \\
(-3.80,2.00)\end{array}$ & 0.54 \\
\hline Age & & & & & $\begin{array}{l}0.01 \\
(-0.08,0.10)\end{array}$ & 0.79 & $\begin{array}{l}0.01 \\
(-0.08,0.10)\end{array}$ & 0.80 \\
\hline \multicolumn{9}{|c|}{180 days } \\
\hline ESG & Reference & & Reference & & Reference & & Reference & \\
\hline IGB & $\begin{array}{l}-4.52 \\
(-8.02,-1.02)\end{array}$ & 0.01 & $\begin{array}{l}-5.03 \\
(-8.89,-1.18)\end{array}$ & 0.01 & $\begin{array}{l}-4.88 \\
(-8.69,-1.06)\end{array}$ & 0.01 & $\begin{array}{l}-4.28 \\
(-8.63,0.07)\end{array}$ & 0.053 \\
\hline $\mathrm{BMI}$ & & & $\begin{array}{l}-0.08 \\
(-0.33,0.17)\end{array}$ & 0.54 & $\begin{array}{l}-0.07 \\
(-0.31,0.18)\end{array}$ & 0.60 & $\begin{array}{l}-0.06 \\
(-0.31,0.19)\end{array}$ & 0.61 \\
\hline Female & & & & & & & $\begin{array}{l}-1.55 \\
(-6.87,3.78)\end{array}$ & 0.56 \\
\hline Age & & & & & $\begin{array}{l}0.11 \\
(-0.03,0.25)\end{array}$ & 0.12 & $\begin{array}{l}0.11 \\
(-0.03,0.25)\end{array}$ & 0.12 \\
\hline \multicolumn{9}{|c|}{360 days } \\
\hline ESG & Reference & & Reference & & Reference & & Reference & \\
\hline IGB & $\begin{array}{l}-7.36 \\
(-12.33,-2.40)\end{array}$ & 0.01 & $\begin{array}{l}-7.10 \\
(-13.31,-0.89)\end{array}$ & 0.03 & $\begin{array}{l}-7.22 \\
(-13.68,-0.76)\end{array}$ & 0.03 & $\begin{array}{l}-9.75 \\
(-16.48,-3.01)\end{array}$ & 0.01 \\
\hline $\mathrm{BMI}$ & & & $\begin{array}{l}0.05 \\
(-0.56,0.66)\end{array}$ & 0.87 & $\begin{array}{l}0.05 \\
(-0.57,0.66)\end{array}$ & 0.88 & $\begin{array}{l}0.08 \\
(-0.51,0.68)\end{array}$ & 0.78 \\
\hline Female & & & & & & & $\begin{array}{l}7.01 \\
(-0.18,14.20)\end{array}$ & 0.06 \\
\hline Age & & & & & $\begin{array}{l}-0.02 \\
(-0.23,0.19)\end{array}$ & 0.87 & $\begin{array}{l}-0.03 \\
(-0.23,0.18)\end{array}$ & 0.79 \\
\hline
\end{tabular}


patients with difficulty maintaining the weight they have lost may not. ESG, comparatively, has not been associated with weight recidivism in our study or prior studies [15, 21-23]. Nevertheless, future studies will need to obtain more data on the longer term weight outcomes for ESG.

Despite the weight recidivism, IGB therapy can certainly play an important role as a bridging therapy to bariatric surgery or to other surgery requiring weight loss (such as orthopedic surgery, cardiac surgery, and transplant, among others). Additionally, as compared to IGB therapy, ESG may make future revisional surgery more difficult, making IGB placement more appropriate where it is felt this may be necessary.

We found that ESG is associated with fewer adverse events than IGB therapy. In our study, $17 \%$ of IGB patients experienced adverse events requiring balloon removal. In a review by Tate and Geliebter [4], the rate of adverse events following IGB placement reached $28.2 \%$, with a serious adverse event rate of $10.5 \%$. Similarly to our study, the reasons reported for early balloon removal were abdominal pain, nausea/vomiting, balloon deflation, and balloon intolerance [3]. Therefore, patients with a low threshold for nausea and pain are likely to better tolerate an ESG. However, unlike IGB-associated adverse events, which completely resolve after balloon removal, adverse events following ESG are more serious and concerning, and are more likely to require medical management.

UGIB is a significant adverse event associated with ESG, as previously reported in other studies [15]. Anticoagulation is an absolute contraindication to IGB placement. Therefore, at our center, IGBs are only placed in patients who can be safely taken off anticoagulants 5 days before and remain off anticoagulants for 1 week following the procedure. Perhaps, similar contraindications to anticoagulation need to be set in place for ESG patients owing to the risk of ulcer formation and resultant bleeding. In addition, it may be safer for patients with an increased risk of bleeding to undergo IGB placement rather than ESG.

Perigastric inflammatory fluid collection has been previously associated with ESG [15] and should be suspected in patients who present with severe abdominal pain or fever post-ESG. Nausea and vomiting post-procedure increases the risk for dehydration in both groups and may require re-admission for intravenous hydration. At our center, patients received a minimum of $2 \mathrm{~L}$ and a maximum of $3 \mathrm{~L}$ of fluids during their stay at the endoscopy suite, thereby mitigating this risk.

The strength of our study is that although it is retrospective, the two groups had one standardized care program and one endoscopist. Ideally, to compare the outcomes of two techniques, all other variables should be held constant. There were no differences between the groups in pre- or post-procedural care, and the 12-month ancillary weight management program was identical following both interventions. Research on dietary interventions that support long-term weight loss emphasizes the importance of regular attendance at a weight management program, which has been significantly associated with weight loss [24]. This has been confirmed in previous research on predictors of ESG success, which shows that weight loss increases significantly in patients with greater nutritional and psychological follow-up [22]. Similarly, greater adherence to follow-up ap- pointments and compliance with diet and exercise have been shown to improve long-term IGB outcomes [7]. Therefore controlling for the weight management care provided, as has been done in this study, is essential to adequately compare two procedures.

An interesting incidental finding relates to patient choice of procedure. The proportion of men undergoing ESG was $41.4 \%$, compared with $2.1 \%$ in the IGB group $(P<0.001)$. As the choice of procedure was a patient decision, this may indicate that ESG is more appealing to men or that IGB therapy is more appealing to women. Previous research has shown that only $20 \%$ of bariatric surgery patients are men [25]. This sex disparity is greater in patients with a low socioeconomic status and patients of certain races [25]. On the other hand, older age and more comorbidities seem to be associated with less sex disparity [25]. Nevertheless, there seems to be an underutilization of bariatric surgery among men, the reasons for which are not fully understood. If ESG is indeed more appealing to obese men than other bariatric interventions, increasing awareness and accessibility of the procedure may increase its utilization.

We argue that our study with its retrospective, single-institutional, and observational design is a fairly accurate illustration of routine clinical practice for the comparison of two EBTs. However, there are several limitations to the be addressed, most notably the presence of selection bias. There were baseline differences between the groups in terms of BMI and sex. This reflects the true population preference for each procedure, but limits our ability to compare the procedures.

Baseline BMI has been shown to significantly affect weight loss outcomes, with higher BMls predicting poorer weight loss. We suspect that this potential bias could have influenced the weight loss outcomes in this study and that the ESG group might have more significant weight loss outcomes compared with the IGB group if the two groups had had comparable baseline BMIs. In addition, the difference in the cost of the procedures may have influenced motivation. Patients willing to pay more for ESG may have been more motivated at baseline.

Perhaps most importantly, this study has patient attrition. Particularly, at the 6-month time point, there is a differential loss to follow-up with greater follow-up in the IGB group. For the IGB group, it can be argued from experience that loss to follow-up at 6 months may be a consequence of a patient's desire to keep the balloon longer if they have had suboptimal weight loss. Loss to follow-up in the ESG cohort at this time point is more likely to occur in patients who are satisfied with their weight loss. The anticipated direction of the results, if we adjust for this bias, would be in the same direction as our current results (ESG showing greater weight loss than IGB therapy). It is also worth mentioning that, despite these potential biases, our data are consistent with the literature.

One final limitation is that patients were included from the beginning of the ESG learning curve for the endoscopist. However, this is unlikely to have affected outcomes as a previous study at our center with the same endoscopist showed a very fast learning curve (7 - 9 patients) for ESG [26].

Both ESG and IGB placement have been shown to improve obesity-related comorbidities, but there have been no com- 
parative studies thus far $[23,27]$. Our study recorded comorbidity data at baseline, but future research may seek to compare the effect of ESG vs. IGB placement on serum biomarkers of obesity-related comorbidities at baseline and over time. Finally, we cannot comment on the tolerability of ESG compared with IGB therapy, as this information was not collected.

Overall, our study shows that ESG and IGB placement are both safe and effective for weight loss over a 12-month period. However, the success of IGB placement is hampered by the weight recidivism that occurs after balloon removal. One difference, from a practical clinical standpoint, is that ESG is a single procedure, whereas IGB therapy requires two procedures: one for balloon insertion and another for removal. Therefore, ESG may be a more desirable EBT than an IGB in some settings owing to its safety, durability, and appeal to patients as a single procedure.

\section{Competing interests}

Mouen A. Khashab is on the medical advisory board for Boston Scientific and Olympus America and is a consultant for Boston Scientific, Olympus America, and Medtronic. Anthony N. Kalloo is a founding member, equity holder, and consultant for Apollo Endosurgery. Vivek Kumbhari is a consultant for Medtronic, Reshape Lifesciences, Boston Scientific, and Apollo Endosurgery; he also receives research support from ERBE USA and Apollo Endosurgery. The remaining authors have nothing to disclose.

\section{References}

[1] Ng M, Fleming T, Robinson M et al. Global, regional, and national prevalence of overweight and obesity in children and adults during 1980-2013: a systematic analysis for the Global Burden of Disease Study 2013. Lancet 2014; 384: $766-781$

[2] Hill C, Khashab MA, Kalloo AN et al. Endoluminal weight loss and metabolic therapies: current and future techniques. Ann N Y Acad Sci 2018; 1411: $36-52$

[3] Yorke E, Switzer NJ, Reso A et al. Intragastric balloon for management of severe obesity: a systematic review. Obes Surg 2016; 26: 2248 2254

[4] Tate CM, Geliebter A. Intragastric Balloon treatment for obesity: review of recent studies. Adv Ther 2017; 34: 1859-1875

[5] Ponce J, Woodman G, Swain J et al. The REDUCE pivotal trial: a prospective, randomized controlled pivotal trial of a dual intragastric balloon for the treatment of obesity. Surg Obes Relat Dis 2015; 11 : $874-881$

[6] Abu Dayyeh BK, Kumar N, Edmundowicz SA et al. ASGE Bariatric Endoscopy Task Force systematic review and meta-analysis assessing the ASGE PIVI thresholds for adopting endoscopic bariatric therapies. Gastrointest Endosc 2015; 82: 425 -438.e425

[7] Kotzampassi K, Grosomanidis V, Papakostas P et al. 500 intragastric balloons: what happens 5 years thereafter? Obes Surg 2012; 22: $896-903$

[8] Genco A, Lopez-Nava G, Wahlen C et al. Multi-centre European experience with intragastric balloon in overweight populations: 13 years of experience. Obes Surg 2013; 23: 515-521
[9] Ponce J, Quebbemann BB, Patterson EJ. Prospective, randomized, multicenter study evaluating safety and efficacy of intragastric dualballoon in obesity. Surg Obes Relat Dis 2013; 9: 290 - 295

[10] Courcoulas A, Abu Dayyeh BK, Eaton L et al. Intragastric balloon as an adjunct to lifestyle intervention: a randomized controlled trial. Int J Obes 2017; 41: $427-433$

[11] Steele CB, Thomas CC, Henley S] et al. Vital signs: trends in incidence of cancers associated with overweight and obesity - United States, 2005-2014. MMWR Morb Mortal Wkly Rep 2017; 66: 1052 - 1058

[12] Vargas EJ, Pesta CM, Bali A et al. Single fluid-filled intragastric balloon safe and effective for inducing weight loss in a real-world population. Clin Gastroenterol Hepatol 2018: doi:10.1016/j.cgh.2018.01.046

[13] Lopez-Nava G, Galvao MP, Bautista-Castano I et al. Endoscopic sleeve gastroplasty: how I do it? Obes Surg 2015; 25: 1534 - 1538

[14] Barola S, Chen YI, Ngamruengphong S et al. Technical aspects of endoscopic sleeve gastroplasty. Gastrointest Endosc 2017; 85: 862

[15] Lopez-Nava G, Sharaiha RZ, Vargas EJ et al. Endoscopic sleeve gastroplasty for obesity: a multicenter study of 248 patients with 24 months follow-up. Obes Surg 2017; 27: 2649 - 2655

[16] Sartoretto A, Sui Z, Hill C et al. Endoscopic sleeve gastroplasty (ESG) is a reproducible and effective endoscopic bariatric therapy suitable for widespread clinical adoption: a large, international multicenter study. Obes Surg 2018: doi:10.1007/s11695-018-3135-x

[17] Barola S, Agnihotri A, Khashab MA et al. Perigastric fluid collection after endoscopic sleeve gastroplasty. Endoscopy 2016; 48: E340E341

[18] Agnihotri A, Xie A, Bartalos C et al. Real-world safety and efficacy of fluid-filled dual intra-gastric balloon for weight loss. Clin Gastroenterol Hepatol 2018: doi:10.1016/j.cgh.2018.02.026

[19] Kumar N, Abu Dayyeh BK, Lopez-Nava Breviere G et al. Endoscopic sutured gastroplasty: procedure evolution from first-in-man cases through current technique. Surg Endosc 2018; 32: 2159-2164

[20] Graus Morales ], Crespo Perez L, Marques A et al. Modified endoscopic gastroplasty for the treatment of obesity. Surg Endosc 2018; 32: $3936-3942$

[21] Novikov AA, Afaneh C, Saumoy M et al. Endoscopic sleeve gastroplasty, laparoscopic sleeve gastrectomy, and laparoscopic band for weight loss: how do they compare? J Gastrointest Surg 2018; 22 : $267-273$

[22] Lopez-Nava G, Galvao M, Bautista-Castano I et al. Endoscopic sleeve gastroplasty with 1-year follow-up: factors predictive of success. Endosc Int Open 2016; 4: E222 - E227

[23] Sharaiha RZ, Kumta NA, Saumoy M et al. Endoscopic sleeve gastroplasty significantly reduces body mass index and metabolic complications in obese patients. Clin Gastroenterol Hepatol 2017; 15: 504 510

[24] Sacks FM, Bray GA, Carey VJ et al. Comparison of weight-loss diets with different compositions of fat, protein, and carbohydrates. NEJM 2009; 360: $859-873$

[25] Fuchs HF, Broderick RC, Harnsberger CR et al. Benefits of bariatric surgery do not reach obese men. J Laparoendosc Adv Surg Tech A 2015; 25: $196-201$

[26] Hill C, El Zein M, Agnihotri A et al. Endoscopic sleeve gastroplasty: the learning curve. Endosc Int Open 2017; 5: E900-E904

[27] Popov VB, Ou A, Schulman AR et al. The impact of intragastric balloons on obesity-related co-morbidities: a systematic review and meta-analysis. Am J Gastroenterol 2017; 112: 429-439 